This is an Accepted Manuscript of an article published by Taylor \& Francis in the International Journal of Training and Research on 21/3/17, available online: http://www.tandfonline.com/ http://dx.doi.org/10.1080/14480220.2017.1299906

To cite this article: Debra Palesy (2017): Brief classroom training sessions for workplace readiness: are they effective?, International Journal of Training Research, DOI:

$10.1080 / 14480220.2017 .1299906$

\title{
Brief Classroom Training Sessions for Workplace Readiness: Are They Effective?
}

\author{
Abstract \\ Classroom training sessions for new home care workers (HCWs) are often brief and 'ad hoc', varying \\ in format and content. Yet, the application of this training may be central to worker and client safety. A \\ qualitative approach was adopted for this inquiry, comprising two separate but related practical studies. \\ In the first, exploratory study, classroom training was observed, and HCWs were interviewed following \\ their classroom training. Based on these findings, a set of interventions were implemented and \\ evaluated in the second study. Findings from the overall inquiry suggest that brief classroom sessions \\ are effective, however a format which encourages the development of dispositional and procedural \\ knowledge is most important. Learning in the classroom may also be enhanced with the provision of a \\ range of written materials to trainees. The paper concludes with a set of recommendations for \\ enhancing the effectiveness of brief classroom training sessions, and suggestions for future research.
}

\section{Key words}

Classroom training, workplace learning, home care workers 


\section{Introduction and background}

This paper reports the findings from an inquiry into the effectiveness of brief classroom training sessions for a group of Australian home care workers (HCWs) learning manual handling. These workers do not have the close support and guidance of more experienced colleagues, as they carry out their work in the privacy of their clients' homes. Instead, they are expected to complete the complex and challenging tasks (e.g., hoisting clients, repositioning in bed, pushing wheelchairs over difficult terrain) that comprise this role after only very perfunctory classroom training, and without direct supervision and support. Concerns about the efficacy of this classroom training have been raised (Faucett, Kang \& Newcomer, 2013; Markannen, Quinn, Galligan, Sama, Brouillette, et al., 2014), as musculoskeletal injuries (predominantly back injuries) in the health and community services sector continue to occur at alarming rates (Clemes, Haslam \& Haslam, 2010; Kay \& Glass, 2011; Martimo, Verbeek, Karppinen, Furlan, Takala, et al., 2008 ). It is proposed that HCWs do not always practice the classroom manual handling techniques they are taught, because of the inadequacy of education being offered in classrooms (Palesy, 2015). Consequently, a primary research focus on understanding how best to support HCWs to learn and adapt their classroom training to the practice of home care, represents an important and worthwhile task. This understanding is critical not only for the safety of HCWs, but also for their care recipients.

\section{The Australian home care sector}

The health and community services sector is Australia's fastest growing workforce sector, as frail older adults and people with disabilities are increasingly opting to be cared for in their own homes rather than move to care facilities (Health \& Community Services Workforce Council, 2012). The majority of home care work is performed by female, middle-aged, low-paid, entry-level workers with low levels of 
English literacy (Australian Bureau of Statistics [ABS], 2014; Australian Institute of Health \& Welfare [AIHW], 2013; Hugo, 2007, 2009; Markannen et al., 2014; Martin \& Healy, 2010). Many HCWs engage in paid care work as a result of previous experience as an unpaid carer at home with a child, an elderly parent, or family member with a disability (Somerville, 2006a). Consequently, home care work is often subject to gendered discrimination (Somerville, 2006b), perceived simply as a mere extension of the nurturing skills of mothers, (Nay \& Garratt, 2002) and based on the honorable ideals of family and love (Markkanen et al., 2014; Meagher, 2006). The suggestion here is that HCWs may disregard their classroom training, as in practice they often feel morally or socially bound to place their own health and safety at risk for that of their clients or 'family members' (Palesy, 2015).

\section{Learning manual handling in the classroom}

While the importance of an appropriately skilled workforce for home care is recognised (Australian Skills Quality Authority, 2013; Martin \& Healy, 2010), job preparation and training frequently fail to prepare HCWs for provision of support to clients with complex needs (Mott, Chau \& Chan, 2007;

Stone, Sutton, Bryant, Adams, \& Squillace, 2013). The work is physically and emotionally challenging, and these pressures potentially impact on recruitment, training and retention of staff (Stone et al., 2013).

Home care in Australia is regulated by legislation and national standards (e.g., Australian Aged Care Quality Agency - Home Care Common Standards, 2014; Australian Government - Quality of Care Principles, 2014). However, besides stipulating the kinds of services that clients should expect to receive in home care, and the need for appropriately trained staff, these standards suggest nothing by way of training content and types of training experiences to achieve this. So, for the most part, service 
providers are encouraged to participate in their own quality assurance processes to ensure uniformity of service provision.

The Certificate III in Aged Care remains the most common qualification for new entrants to the home and community services sector (Australian Skills Quality Authority, 2013). This qualification is designed to assist HCWs to become 'work ready', and includes a range of subjects focused on working safely with clients, and providing individualised personal care. However, formal qualifications are not mandatory for entry into home care work and, even when offered, the suggestion is that training programs are largely too short and allow insufficient time in a workplace for sufficient skills development (Australian Skills Quality Authority, 2013).

Beyond formal qualifications, however, Martin and Healy (2010) suggest a range of other learning experiences that enable $\mathrm{HCW}$ s to handle the complex issues and problems encountered in their work. In home care, most of these 'other' learning experiences are provided in the form of in-house training such as first aid, medication management, infection control and manual handling, with service providers differing greatly in the amount and types of in-house training offered. While larger organisations may offer more systematic training programs, smaller agencies tend to provide more adhoc and fewer hours of training, citing financial constraints or workers 'already skilled enough' as reasons why this is the case (Baldock \& Mulligan, 1999), and many HCWs receive no formal induction training for their roles at all (Rimfire Resources and National Disability Service Australia; 2010) Hence, HCWs have an encompassing role in providing direct and often challenging care to people in their own homes, often with little or no formal training qualifications.

When classroom training is offered as part of a HCW's orientation to an organisation, sessions are anywhere from 10 minutes to four hours in duration (Aylward, Stolee, Keat \& Johncox, 2003; Baldock \& Mulligan, 1999; Bernoth, 2009), vary in format, and are often competency-based. 
'Competency', however, requires the consistent application of knowledge and skill to the standard of performance required in the workplace, and embodies the ability to transfer and apply skills and knowledge to new circumstances (Australian Skills Quality Authority, 2013). A concern then, is that in competency-based classroom manual handling training, staff may be deemed competent after a single assessment in a spacious, unhurried, modern and fully equipped classroom, and are then required to transfer their learning to challenging environments in clients' homes (e.g., bulky furniture, pets, thick carpets, a non-height adjustable bed and severe time constraints, clients with varying levels and complexity of support requirements). This lack of preparation for the HCW role leads to poor job satisfaction and high staff turnover (Manthorpe \& Martineau, 2008), and work-related back pain and injuries, which, according to Safe Work Australia (2014), are the most prevalent, costly and disruptive in the developed world. Moreover, unsafe manual handling techniques can have serious implications for the care recipients also, with injuries such as bruising, skin tears, pressure sores and emotional trauma frequently reported as a consequence of poor manual handling ( "Nursing home found in breach of act over accident with a hoist”, 2008; Tuohy-Main, 1997). Consequently, the format and brevity of classroom training creates a serious set of challenges for both HCWs and their clients, as they seek to apply what they are learning in brief classroom training to the privacy and intimacy of clients' home, without access to direct supervision and support.

\section{Method}

This inquiry adopted a case study approach, which aims to facilitate understanding 'real' problems, improve practices, and support or influence better decision making (Merriam, 2014). The 'case' was a home care organisation whose staff provide a range of supports to clients, including manual handling activities such as people handling (e.g., showering, toileting), and non-people handling (e.g., shopping, 
housekeeping). Two separate but related practical studies (i.e., Study A and Study B) were conducted for the inquiry. Study A comprised an exploration of a home care organisation's classroom manual handling training situation, and culminated in a set of interventions for HCW classroom manual handling training to improve training practices which were enacted and appraised in Study B. Informant selection was non-random and based on convenience. Seven new HCW trainees who were enrolled in upcoming induction training were recruited for Study A. These trainees consisted of two males and five females varying in age, cultural background, and life experience, including previous education and work. A further seven new HCWs were recruited as informants for Study B, comprising three males and four females, again with varying ages and past personal experiences. Data were also gathered from the organisation's manager and manual handling trainer. So, despite its small scale, diverse gender, age and backgrounds of the informants yielded rich data for the inquiry. For the purposes of confidentiality and de-identification, all informants (and the organisation) were assigned pseudonyms.

Qualitative data were obtained from in-depth semi-structured interviews with each informant; direct observation of the classroom training sessions, and perusal of the training curriculum. Data were collected at three points: (a) in the classroom; (b) four weeks post-classroom training; and (c) 12 weeks post-classroom training. Interviews and observations aimed to capture informants' attitudes and reactions to classroom training and their intentions to apply what they had learnt to their workplaces, and also aimed to identify ways in which new HCWs were transferring and adapting their newly learned manual handling skills. Five key areas guided the interview questioning: (a) content learned in classroom training; (b) intention to apply this training to the workplace; (c) extent to which this application is actually occurring; (d) factors facilitating or hindering the application of classroom training; and (e) views about how best to support HHAs learning the requirements for their roles. 
Inductive reasoning principles were used to analyse the data, by searching for patterns and emerging themes in relation to classroom training experiences (Blaikie, 2009; Thomas, 2006). Ultimately, data analysis aimed to determine whether brief classroom training sessions for HCWs were effective, the factors which facilitated or hindered the application of classroom-taught manual handling techniques to the workplace, and propose suggestions for better supporting HCWs to learn and enact safe home care.

Limitations were considered prior to undertaking this study. Firstly, only a small number of informants were recruited for the inquiry, and secondly, data was not collected beyond the 12 week period, so little is known about how skills and knowledge acquisition proceeded beyond this time frame. While the intention was to obtain qualitative data from ten $\mathrm{HCW}$ informants for each practical study (A and B), only seven expressed an interest for each study and remained committed to the study period. Low staff retention and high turnover of these workers remains a challenge in the home care sector (Radford, Shacklock \& Bradley, 2015), which in turn influences informant recruitment and time frames for data collection. However, Blaikie (2009) suggests that qualitative research methods are by nature resource-intensive, and therefore smaller samples and timeframes are appropriate. Still, and to mitigate this potential limitation, approaches were taken to make the study systematic and valid. These approaches included one researcher only collecting data and the development of interview guides with the same pre-determined questions for all informants. Data collection guides were briefly trialed and refined with two 'test' HCWs who were already working in the field. Furthermore, an additional researcher was engaged to independently analyse the interview data as an inter-rater reliability strategy. So, data collected at all points during the study were rich, trustworthy, and analysed with sincerity. As each case study has many unique aspects another limitation of this study may be its usefulness in generalising (Wiersma, 2009). The Australian home care sector workforce is 
predominantly female (AIHW, 2013), yet of the fourteen HCW informants recruited across both practical studies, six were male. These informants however, were the only ones who volunteered to participate, and who remained committed to each 12-week period. Moreover, the selection of only one home care organisation to explore and analyse all $\mathrm{HCWs}$, may restrict any claims for generalising findings to other home care situations (Blaikie, 2009). To mitigate this risk, the site for study was selected as a case because its features were representative of many Australian home care providers in terms of manual handling tasks, and training programs offered.

Ethical approval was granted prior to conducting the research. Information packages were provided, and consent was obtained from informants prior to collecting data for the study.

\section{Findings}

Appraisal of the organisation's existing manual handling curriculum in Study A found the classroom training session for HCWs to be brief and largely didactic. Of the 60 minutes allocated to this session, 45 minutes comprised imparting a series of manual handling principles. The remaining 15 minutes was dedicated to small group work, where new workers practiced hoist transfers of their peers from a bed to a chair, and correct pushing of a wheelchair.

Three main themes emerged from the interview data in relation to the format and content of this classroom training for HCWs. These themes were: (a) practical small group activities are the most useful component of the classroom training session; (b) regular 'refresher' training sessions may be a way to consolidate and extend safe manual handling principles for home care; and (c) written materials such as a classroom handout and organisational policies and procedures are important for supporting classroom training. These three findings are presented in Table 1. In the left-hand column, the theme is 
identified. In the right-hand column, samples of informant responses in relation to each theme are provided. 
Table 1. Classroom Training Considerations: Findings from Study A

\section{Classroom training theme Sample responses}

Practical, small group activities are important in 'They're so isolated you know, this [classroom training] is the only opportunity to talk to their classroom training

fellow workers...' (Sue, manual handling trainer)

In addition to the initial classroom training, refreshing manual handling knowledge regularly in the classroom would be helpful in extending and consolidating manual handling skills

Written materials help to consolidate classroom training
'[The existing small group work encourages] serious, focused conversations ... talking about their clients and what they find challenging, trying to get ideas from each other, trying to support each other ... really, they're just trying to get a feel for the work - surely that's something [classroom training] should be encouraging'. (Sue, manual handling trainer)

'You're on your own so much you've got to be practical, and a bit tough... So it's good to talk to other people in the classroom, and get up and do stuff'. (Jen, trainee)

'We probably do need more [opportunities for staff to] share some of their experiences and challenges'. (Mark, manager)

'I really liked being in the classroom and learning all the new stuff, but it'd be great to go over it again you know? The more you do things, the more times you go over them with an expert, the more likely you are to retain it'. (Meg, trainee)

'We need to be able to discuss things after we've been out there for a while'. (Di, trainee)

'[If] I could actually talk to [other home care workers] about what was going on and get some practical ideas... more of the training would have sunk in then'. (Bree, trainee)

'I've had [the handout] out a few times you know, going over stuff, the basics. I didn't need to in the beginning but as time goes by I've lost a lot of it, so it's good to go back over things'. (Rick, trainee)

'[The classroom trainer] gave us...the rules and policies, the reasons why we should follow them and all the terrible things that could happen to us and the client if we don't. That's why I [enact safe manual handling techniques] all the time now'. (Di, trainee)

'Safe working instructions...pictures of everything, like step-by-step on how to put someone in a hoist... anything that'll spell it out for us, that'll help cement the training'. [Rick, trainee] 
Responses in Table 1 suggest that practical manual handling activities and group interaction in the classroom provided a way for new HCWs to offset the socially-isolated circumstances in which these techniques were enacted. These classroom interactions enabled trainees to develop a disposition for the work, and become embodied in their HCW roles. That is, through opportunities to observe, model, rehearse and discuss manual tasks, new workers would view their work as being more than a series of skills and tasks to be learned and replicated in the workplace (Somerville, 2006b). Indeed, informants of Study A requested a return to the classroom for this purpose of interacting with others and further consolidating their learning. Moreover, informants appreciated written materials as a means of enhancing their learning both in the classroom and workplace.

Consequently, based on the observation of the classroom training, and informants' interview responses in relation to classroom training in the exploratory study, three interventions were proposed for trial in Study B. These interventions were: (a) a revised initial classroom training format; (b) a return to the classroom after eight weeks for 'refresher' training; and (c) provision of various written materials both in the classroom and in the workplace. The revised initial classroom training included extending the session from one hour to two hours. The session comprised only 15 minutes of didactic, where basic manual handling concepts were conveyed, and the remaining one-hour and 15 minutes of classroom time was dedicated to providing opportunities for trainees to explore and develop a disposition for their home care role, and rehearse key manual handling tasks in small groups. For the refresher training, HCWs were supported to workshop authentic manual handling scenarios that had been encountered in various clients' homes. Facilitated by a manual handling expert, these two-hour sessions comprised small group discussion and practical applications of various manual handling techniques. Written materials to support the classroom training were provided in the form of a classroom handout, along with organisational policies and procedures, and step-by-step instructions for 
key manual handling tasks in the workplace. Seven new informants were recruited for this second study, who were all unaware that the organisation had offered training in the previous format (i.e., that outlined in Study A). By following a new group of HCWs over the 12 weeks from their initial induction training, the aim was to compare and contrast interview responses and determine the effectiveness of the classroom training interventions. Findings from these three interventions are presented in Table 2. In the left-hand column, the theme is identified. In the right-hand column, samples of informant responses in relation to each theme are provided. 
Table 2. Classroom Training Considerations: Findings from Study B

\begin{tabular}{l} 
Classroom training theme \\
\hline Revised initial classroom training format: \\
- $\quad$ Session extended from one to two \\
hours \\
- $\quad$ Less didactic - basic principles only \\
- More focus on practical activities \\
- $\quad$ More focus on developing a \\
disposition for the HCW role
\end{tabular}

Classroom refresher training eight weeks after initial training and time spent on-the-job

\section{Sample responses}

'It flowed really well ... to discuss ... the nature of support work in general, and then continue that discussion during the practical ... getting people to think about how their personality and their approach might affect the clients and the way they're handled ... I think [the trainees] relaxed when they knew that it is OK to just be themselves out there.' (Sue, trainer)

'It allowed us to work together ... really work things out. We went through each activity at a reasonable pace, but at the same time receive input from others. It was great to talk to other people and get their ideas about how they go about things.' (Anne, trainee)

'...it won't hurt the budget, it may even save us money in recruitment costs and lost time injuries' (Mark, manager).

'... [learning] the basics [in the initial classroom session] ... and then building on them helped ... by the time we all came back to the classroom there was a level of knowledge there, so we could pick up where we left off....' (Dan, trainee)

'[Refresher training is]... the real thing. It's not textbook stuff. They were real situations...that our fellow [HCWs] had experienced ... so workshopping the specifics was good.' (Mike, trainee)

'Even though the [scenarios presented in the refresher] didn't apply to me, I could picture how I would respond in each situation ... I already had the answers in my head to these manual handling problems, about how I would face them. And I thought to myself, 'wow, you've come a long way, you actually do know something about this job.' (Barb, trainee)

\section{Written materials}

- Classroom training handout

- Organisational policies and procedures

- Step-by-step instructions for key tasks
'I made notes on [the handout] and ... read over it a few times, just to check that I'm doing the right thing. It's good to have a reference. It feels more professional, and supportive.' (Anne, trainee)

'... [organisational policies and procedures] ... remind[s] everyone that we're professionals'. (Nat, trainee)

'... just knowing that those supports are there, even if you don't need them or use them, well that's going to help you do a good job, and do good manual handling. (Anne, trainee) 
Responses in Table 2 suggest that informants of Study B may have been better prepared to enact safe manual handling practices in their clients' private homes. In Study A, informants mentioned being 'isolated' and 'on [their] own', and called for opportunities for more classroom interaction. However, in Study B, informants reported their classroom training sessions as a way of enhancing their learning and assisting them to 'do a good job' of supporting clients in their private homes. A further synthesis of the findings from Studies A and B follows in the next section.

\section{Discussion}

From the findings presented in Tables 1 and 2, three concepts are the focus of discussion in this section: (a) the types of knowledge required for learning occupational practice; (b) classroom training delivery methods for enhancing workplace readiness; and (c) the importance of written materials to support classroom training. These concepts will now be briefly elaborated.

\section{Identifying the type of knowledge required for safe workplace practices}

The term 'knowledge' is used here in reference to the conceptual and procedural cognitive structures that are organised, interlinked and held in memory. While the usual distinction is between conceptual and procedural knowledge (Anderson, 1982; Glaser, 1984), or knowledge 'that' and knowledge 'how' respectively (Ryle, 1949), it is proposed that these kinds of knowledge are inherently dispositional and may underpin how cognitive structures are deployed (Billett, 1997; Perkins, Jay, \& Tishman, 1993).

Conceptual knowledge, or knowledge 'that' (Ryle, 1949), comprises concepts, facts, assertions and propositions. This type of knowledge is differentiated by levels of increasing complexity, ranging from simple facts through to deeper levels of conceptualisation and understanding. As learners secure concepts and can identify relationships and interconnectedness amongst them, depth of understanding increases (Billett, 2013; Prawat, 1989). According to Pea (1987) and Royer (1979), a deep level of 
conceptual knowledge enables the abstraction of principles and concepts, which may lead to effective complex problem solving and transfer of knowledge to novel situations.

While 'the basics' were deemed to be important for informants of this inquiry, there may be time limitations in developing a deep level of this type of knowledge in brief classroom training sessions. However, the constantly evolving nature of work practices, and the complex interplay of factors that influence work performance, means that there may be no limits to a person's depth of understanding (Billett, 2001). So, despite the brevity of the current classroom training sessions, it may still be possible for HCWs to develop the kinds and depth of conceptual knowledge that is most likely required in their workplaces. This includes the range of complex and non-routine situations that they may encounter on a regular basis. It follows then that, on its own terms, a brief classroom training session does not mean that the required level of development cannot be realised. However, on the other hand, there is no guarantee that this development will occur in practice settings unless individuals have the capacities and interest to learn this knowledge. The same is likely to be true of procedural development.

Procedural knowledge, or knowledge 'how' (Ryle, 1949), comprises techniques, skills and procedures used to enable skilful action (Stevenson, 1994). It is the knowledge that we need and apply to 'do' things. This procedural type of learning was also identified in the 1970s by Scandura (1973, 1984) who suggested that knowledge consists of a set of rules (or components) to be determined, and then applied as a sequence of procedures (or operations) to a problem domain in order to achieve a solution. Scandura $(1973,1984)$ proposes that the use of lower-order rules, which represent the most basic components that a learner needs to know for solving a well-defined problem, leads to the development of higher-order rules, which can then be used to solve more complex problems. 
As with the limitations in developing a deep level of conceptual knowledge in brief classroom training sessions, there are also potential challenges in developing the higher orders of procedural knowledge required by HCWs for safe work practices in these sessions. As Billett (2011a) points out, learning to perform work tasks effectively is underpinned by opportunities to observe, model and repeatedly rehearse them. So, a brief classroom training session, followed by negligible direct peer, expert or supervisor guidance as they attempt to adapt what they have learned to new circumstances in their workplaces, may support the development of first-order rules only.

An additional concern here is the lack of time for these workers to develop a disposition for their home care role. Learning safe manual handling techniques in classrooms as a series of concepts and procedures, means that while workers have an understanding of basic body principles, and can carry out the very personal aspects of care, they lack the time necessary to develop an awareness of their own bodies (Somerville \& Bernoth, 2001), and the importance of working safely. Consequently dispositions, that is, the personal attitudes, values, affect, interest and identities that may influence the differences between what learners are capable of doing and what tasks they actually undertake (Billett, 2013; Collin, 2009; Collin, Paloniemi, Virtanen \& Eteläpelto, 2008; Eteläpelto, Vähäsantanen, Hökkä \& Paloniemi, 2013; Hodkinson, Biesta \& James, 2008; Perkins et al., 1993; Prawat, 1989) may be central to how HCWs decide to conduct safe manual handling techniques in a clients' homes. This is supported by Braun, Cheang and Shigeta. (2005), whose study of essential curriculum features for care workers in aged care found that some of the most meaningful learning for these workers occurred when informants were encouraged to share personal accounts and challenges in care work and, in this way, construct meaning from their work experiences. In the classroom, the stories of these workers provided 'teachable moments' through which the key concepts could be explored (p. 120). 
In sum, brief classroom training sessions may be effective in preparing $\mathrm{HCW}$ sor the workplace. However, the types of knowledge required for safe workplace practices conveyed in these sessions is important. A training session that conveys basic concepts only, and focuses largely on encouraging the development of worker dispositions and the application of procedural knowledge, may enhance workplace readiness. This development and application may be supported by brief didactic instruction, followed by group work and practical activities, which is discussed in the next section.

\section{Classroom training delivery methods for enhancing workplace readiness}

Despite all the criticisms that have been directed at didacticism and lecture-style delivery in adult education, the lecture remains one the most frequently employed techniques for delivery of conceptual knowledge (Banning, 2005). Walkin (2000) supports didacticism as a means of transmitting large amounts of factual information to an audience, and suggests that it may also have additional benefits when the content is new to the majority of students, or if the learners are teacher-dependent, anxious or disorganised as learners. This may be true of new HCWs, who have cited fear of failure, limited understanding of theoretical requirements, feelings of being overwhelmed by work, and conflict with family commitments as impediments to learning (Zemlin, 2014). However, new HCWs may not have the experience or readiness to engage with didactic presentations, and the learning activities (e.g., notetaking, summarising key points) that accompany them. Consequently, other methods, particularly small group work and practical activities, should be incorporated into brief classroom training sessions.

Properly structured group projects may help students to develop a range of skills that are relevant to both group and individual work (Caruso \& Woolley, 2008). This is particularly true for HCWs, who are often required to apply facts and ideas learned in a classroom to the real-life situations of caring for their clients, without direct supervision or support. According to Billings and Halstead 
(2009), this transition requires a risk-free environment conducive to active student participation. Group tasks in the classroom, combined with the necessary peer interaction, may assist in enhancing HCW skills such as critical thinking (e.g., negotiating challenging physical environments when manual handling in clients' homes), task breakdown (e.g., systematically applying body principles to set manual handling tasks), effective time management (e.g., prioritising various aspects of support to ensure that the clients' most important needs are met), refinement of understanding through discussion and explanation, giving and receiving performance feedback, challenging of assumptions, and development of stronger communication skills (Billings \& Halstead, 2009; Caruso \& Woolley, 2008; Mannix \& Neale, 2005). Moreover, group work may also assist students in developing skills specific to collaborative efforts, allowing them to share diverse perspectives, pool knowledge and skills, develop new approaches to learning, find appropriate peers to emulate, and establish a shared identity with other group members (Caruso \& Woolley, 2008; Mannix \& Neale, 2005).

While the potential learning benefits of group work and peer interaction are significant, simply assigning group work in the classroom is no guarantee that these goals will be achieved. According to Loftin, Davis, and Hartin (2010), not all students enjoy active participation in the classroom, preferring to be passive learners instead. These authors suggest a number of reasons for this, including negative participators (e.g., people who monopolise the discussion, disagreeable participants), fear of peer disapproval, students speaking English as a second language, large class sizes, and lack of class preparation. Therefore, strategies should be implemented to gain maximum group participation of all trainees. Pre-training strategies may include limiting class sizes, enlisting trainees to choose authentic scenarios relevant to their work in preparation for discussion with their peers, and the engagement of an expert facilitator who will acknowledge and praise input from participants (Palesy, 2015). In the 
classroom, removal of desks and configuring of the chairs to allow for visual interaction may also maximise trainee participation (Palesy, 2015).

Informants of this inquiry valued the group work and peer interaction, and the perceived 'fun' afforded in their brief classroom training sessions. Indeed, they requested a return to the classroom for refresher training, as a means of sharing information and ideas, providing instruction and debriefing. This type of engagement as a means of assisting learning is reflected in research conducted by Orr (1990). In his observations of Xerox photocopier technicians, Orr found that the exchange of 'war stories' - by discussing work-related issues as they gathered around water coolers, during lunch breaks or at social meetings - led easily to a shared understanding and creation of new knowledge. Billett (2011b), too, in his study of mature-aged Singaporean workers, reported that older workers did not want to be treated as students who needed instruction from others, but preferred instead to engage in 'dialogue forums'. These forums, held in or around the workplace (e.g., on-the-job, meal breaks), provided rich learning opportunities whereby workers could share their knowledge and learn from others at the same time, without positioning themselves in a teacher-student relationship (Billett, 2011b). These accounts suggest that besides structured classroom training experiences, other, less formal opportunities to share and exchange work-related knowledge may also enhance learning in classroom training sessions.

In sum, brief classroom training sessions may enhance workplace readiness. However, training delivery methods should be carefully selected. While brief didactic instruction may have a legitimate place in classroom training, small group work and practical activities which are relevant to the workplace, and provide opportunities for engagement, may further facilitate the development of conceptual, procedural and dispositional knowledge. This development may also be supported by written materials, which is discussed in the next section. 


\section{Written materials as a form of learning support}

Besides the format and content, other forms of learning support, such as written materials, may also support learning in brief classroom training sessions. Informants of this inquiry called for a range of written materials, such as a classroom training handout, copies of organisational policies and procedures, and step-by-step instructions (with photographic depictions) of how to perform key manual handling tasks.

Reliance on policies and procedures as a major source of practice knowledge is supported in studies of nurses (Hauck, Winsett \& Kuric, 2013; Melnyk, Gallagher-Ford, Long \& Fineout-Overholt, 2014). Isolation (e.g., in home care settings), limited access to computers, and time constraints may be factors which contribute to this trust in policies and procedures as the main source of information from an organisation (Estabrooks, Floyd, Scott-Findlay, O’Leary \& Gushta, 2003). The same may be true for HCWs. In clients' homes, where shifts are often only of 2-3 hours duration, there is little time to access other sources of information such as newspapers and journal articles. Moreover, the nature of these workers (as previously discussed) suggests that they may not have the skills required to access, read and critically appraise other sources of information, and may believe they lack the authority to implement any findings into practice (Gerrish \& Clayton, 2004 ). Therefore, in addition to policies and

procedures, a range of other materials (photos, handouts) may augment new HCWs' classroom training sessions.

These materials may be viewed as 'instructional scaffolding' (Bruner, 1975; Wood, Bruner \& Ross, 1976), namely, a form of support provided by others (e.g., teacher, expert) to assist these workers to progress their learning (Sawyer, 2006). A typical trajectory is for this scaffolding, or learning support, to be removed once individuals master the task (Brown \& Palincsar, 1989; Wertsch, 1985) and for a gradual removal, or 'fading', to be initiated by the teacher (Collins, Brown \& Newman, 1989). 
However, in the case of this inquiry's informants, they took the decision to remove the learning support (i.e., written materials) themselves. That is, they managed their own scaffolding.

Informants in Study B reported the most frequent or regular use of the written materials as a learning support, or scaffolding (Bruner, 1975; Wood et al., 1976) in the first 4 weeks of practice. Then, as these HCWs became more confident in their roles, they took the decision to remove the scaffolding for themselves. So, at 12 weeks, all informants were working independently, and enacting safe manual handling techniques without their written materials. However, even when not needed, these materials provided an implicit form of support, described by one informant as 'a safety net', and also claimed that it was important for these to remain in the workplace as continued supports for new HCWs.

Consequently, a recommendation from this study is to provide a uniform set of written materials both in the classroom and workplace, with which new workers may engage as required. These materials may include a comprehensive organisational policy and procedure manual, care plans, safe operating instructions and photographic depictions of certain tasks, which are revised and updated regularly by the organisation. These written materials represent a form of organisational support which may enhance the effectiveness of brief classroom training sessions.

Recommendations from the preceding discussion are summarised as a framework for enhancing the effectiveness of brief classroom training session in Table 3. The left-hand column states the recommendation. The centre column lists the strategies for implementing each of the recommendations, and the right-hand column suggests the expected outcomes for workers' learning as a result of these strategies. 
Table 3. Framework for Enhancing Learning in Brief Classroom Training Sessions

\begin{tabular}{|c|c|c|}
\hline Recommendation & Strategies & Potential outcomes \\
\hline \multirow{8}{*}{$\begin{array}{l}\text { Consideration for type of } \\
\text { knowledge conveyed }\end{array}$} & Initial classroom training: & \\
\hline & Convey basic concepts only & $\begin{array}{l}\text { Establishment of superficial level of conceptual } \\
\text { knowledge }\end{array}$ \\
\hline & $\begin{array}{l}\text { Focus on development of procedural knowledge by rehearsing key } \\
\text { tasks }\end{array}$ & $\begin{array}{l}\text { Initial development of lower-order rules, for later } \\
\text { application to higher order, more complex tasks }\end{array}$ \\
\hline & $\begin{array}{l}\text { Encourage trainees to establish a positive disposition for their role } \\
\text { - allocate time for sharing personal experiences, histories etc. }\end{array}$ & $\begin{array}{l}\text { Dispositional knowledge - workers 'get a feel for' the } \\
\text { work }\end{array}$ \\
\hline & Refresher classroom training: & \\
\hline & Application of basic concepts to a range of more complex tasks & $\begin{array}{l}\text { Deepening level of conceptual knowledge, } \\
\text { abstraction of concepts for problem solving and } \\
\text { transfer to novel situations }\end{array}$ \\
\hline & $\begin{array}{l}\text { Rehearsal of procedures by workshopping authentic scenarios } \\
\text { encountered in workplace }\end{array}$ & Development of higher-order procedures \\
\hline & $\begin{array}{l}\text { Continued personal storytelling and sharing of experiences } \\
\text { associated with the work }\end{array}$ & Embodiment in role \\
\hline \multirow[t]{4}{*}{$\begin{array}{l}\text { Consideration for delivery } \\
\text { method }\end{array}$} & $\begin{array}{l}\text { Classroom training sessions to be brief in duration (e.g., } 1-2 \\
\text { hours) }\end{array}$ & $\begin{array}{l}\text { Shorter time frames less overwhelming for new } \\
\text { workers - may allay anxieties of new workers about } \\
\text { being in classroom }\end{array}$ \\
\hline & $\begin{array}{l}\text { Encourage group tasks and peer interaction, including informal } \\
\text { opportunities for engagement }\end{array}$ & $\begin{array}{l}\text { Development of critical thinking skills; further } \\
\text { development of disposition for role through formation } \\
\text { of a shared identity }\end{array}$ \\
\hline & Provide opportunities to practice a range of procedural tasks & $\begin{array}{l}\text { Development and deepening of procedural } \\
\text { knowledge }\end{array}$ \\
\hline & $\begin{array}{l}\text { Configuration of classroom and cohort - limit class sizes, remove } \\
\text { desks and arrange chairs to allow for visual interaction }\end{array}$ & $\begin{array}{l}\text { Maximum participation in all classroom training } \\
\text { activities supported }\end{array}$ \\
\hline \multirow[t]{2}{*}{ Written materials } & $\begin{array}{l}\text { Provide a uniform set of written materials in the workplace (e.g., } \\
\text { organisational policies, step-by-step instructions of how to perform } \\
\text { key tasks, photographic depictions) }\end{array}$ & $\begin{array}{l}\text { A range of resources as instructional scaffolding to } \\
\text { accommodate multiple learning styles }\end{array}$ \\
\hline & $\begin{array}{l}\text { No rigid stipulations about how these written materials should be } \\
\text { accessed or utilised }\end{array}$ & $\begin{array}{l}\text { Acknowledgement of individuals' personally unique } \\
\text { ways of acquiring work-related skills and knowledge }\end{array}$ \\
\hline
\end{tabular}


Table 3 summarises each recommendation proposed in the discussion section, outlines some strategies for implementing these recommendations, and suggests enhanced outcomes for workplace learning. The outcomes here relate to the development and enhancement of conceptual, procedural and dispositional knowledge through effective classroom training. However, implementing these strategies for HCWs may also lead to more specific outcomes. The interventions proposed in Table 3 may also encourage HCWs to prioritise care of their own bodies, work safely and avoid injury. In this way, a more sustainable workforce is developed, with a lower risk of physical and emotional burnout of HCWs, reduction in staff turnover rates and, ultimately, safer care for service clients.

\section{Conclusion}

This inquiry aimed to understand how best to support HCWs to learn and adapt their classroom-taught manual handling training to the relatively socially isolated practice of home care. It is concluded that brief classroom training sessions for HCWs are effective in enhancing workplace readiness. However, three main recommendations are proposed. Firstly, and as summarised in Table 3, content of these sessions are important. Brief classroom training should convey basic concepts only, and focus largely on developing dispositional and procedural knowledge required for workplace readiness. Secondly, training delivery methods should be considered. Dispositional and procedural knowledge may best be supported in a classroom training format that includes brief didactic, with a major component of group work, practical activities and opportunities for engagement. Finally, brief classroom training may be augmented by the provision of a set of written materials, a form of 'instructional scaffolding' with which new workers may engage on an 'as needed' basis.

As a concluding point, the HCW workforce is expanding rapidly, and therefore more comprehensive and ongoing profiling of these workers as learners is needed. A significant effort needs 
to be invested into providing appropriate job preparation, continuing education and training that will prepare $\mathrm{HCW}$ s to meet the challenges associated with learning and working safely in the relative privacy of people's homes.

\section{References}

Anderson, J. R. (1982). Acquisition of cognitive skill. Psychological Review, 89(4), 369-406.

Australian Aged Care Quality Agency (2014). Home Care Common Standards (2014). Canberra:

Commonwealth Government of Australia.

Australian Bureau of Statistics. (2014). Employee Earnings and Hours, Australia, May 2014 (cat. no. 6306.0) published on 22nd January 2015. Retrieved from www.abs.gov.au/ausstats

Australian Government. (2014) Quality of Care Principles. Canberra: Commonwealth Government of Australia

Australian Institute of Health and Welfare. (2013). Australia's welfare 2013 (Cat. no. AUS 174). Canberra: AIHW.

Australian Institute of Health and Welfare. (2009). Health and community services labour force. National health labour force series number 42 (Cat. no. HWL 43). Canberra: AIHW.

Australian Skills Training Authority. (2013). Report: Training for aged and community care in Australia. Canberra: Australian Government

Aylward, S., Stolee, P., Keat, N., \& Johncox, V. (2003). Effectiveness of continuing education in longterm care: A literature review. The Gerontologist, 43(2), 259-271.

Baldock, C., \& Mulligan, D. (1999). Restructuring and women workers in Australian home care. Resources for Feminist Research, 27(3/4), 13-27. 
Banning, M. (2005). Approaches to teaching: Current opinions and related research. Nurse Education Today, 25(7), 502-508.

Bernoth, M. (2009). '... and the word was made flesh' - The impact of discourses of embodiment in promoting safe manual handling practice in aged care (Doctoral Dissertation, Monash University, Victoria, Australia).

Billett, S. (1997). Dispositions, vocational knowledge and development: Sources and consequences. Australian and New Zealand Journal of Vocational Education Research, 5(1), 1-26.

Billett, S. (2001). Learning in the workplace: Strategies for effective practice. NSW, Australia: Allen \& Unwin.

Billett, S. (2011a). Learning in the circumstances of work: The didactics of practice. Éducation et didactique, 5(2), 125-146.

Billett, S. (2011b). Promoting lifelong employability for workforce aged over 45: Singaporean workers' perspectives. International Journal of Continuing Education and Lifelong Learning, 3(2), 57-73.

Billett, S. (2013). Recasting transfer as a socio-personal process of adaptable learning. Educational Research Review, 8, 5-13.

Billings, D., \& Halstead, J. (2009). Teaching in nursing: A guide for faculty $\left(2^{\text {nd }}\right.$ ed.). St Louis, MO: Elsevier Saunders

Blaikie, N. (2009). Designing social research. UK: Polity.

Braun, K. L., Cheang, M., \& Shigeta, D. (2005). Increasing knowledge, skills and empathy among direct care workers in elder care: A preliminary study of an active-learning model. The Gerontologist, 45(1), 118-124. 
Brown, A. L., \& Palincsar, A. S. (1989). Guided, cooperative learning and individual knowledge acquisition. In L. B. Resnick (Ed.), Knowing, learning, and instruction: Essays in honor of Robert Glaser (pp. 393-451). Hillsdale, NJ: L. Erlbaum Associates.

Bruner, J. (1975). The ontogenesis of speech acts. Journal of Child Language, 2, 1-19.

Caruso, H. M., \& Wooley, A. W. (2008). Harnessing the power of emergent interdependence to promote diverse team collaboration. Diversity and Groups, 11, 245-266.

Clemes, S., Haslam, C., \& Haslam, R. (2010). What constitutes effective manual handling training? A systematic review. Occupational Medicine, 60, 101-107.

Collin, K. (2009). Work-related identity in individual and social learning at work. Journal of Workplace Learning, 21(1), 23-35.

Collin, K., Paloniemi, S., Virtanen, A., \& Eteläpelto, A. (2008). Constraints and challenges on learning and construction of identities at work. Vocations and Learning, 1(3), 191-210.

Collins, A., Brown, J. S., \& Newman, S. E. (1989). Cognitive apprenticeship: Teaching the crafts of reading, writing, and mathematics. Knowing, learning, and instruction: Essays in honor of Robert Glaser, 18, 32-42.

Estabrooks, C. A., Floyd, J. A., Scott-Findlay, S., O’Leary, K. A., \& Gushta, M. (2003). Individual determinants of research utilization: A systematic review. Journal of Advanced Nursing, 43, 506-520.

Eteläpelto, A., Vähäsantanen, K., Hökkä, P., \& Paloniemi, S. (2013). What is agency? Conceptualizing professional agency at work. Educational Research Review, 10, 45-65.

Faucett, J., Kang, T., \& Newcomer, R. (2013). Personal service assistance: Musculoskeletal disorders and injuries in consumer-directed home care. American Journal of Industrial Medicine, 56, 454-468. 
Franklin, N., \& Melville, P. (2015). Competency assessment tools: An exploration of the pedagogical issues facing competency assessment for nurses in the clinical environment. Collegian, 22, 2531.

Gerrish, K., \& Clayton, J. (2004). Promoting evidence-based practice: An organisational approach. Journal of Nursing Management, 12, 114-123.

Glaser, R. (1984). Education and thinking - the role of knowledge. American Psychologist, 39(2), 93104.

Health and Community Services Workforce Council. (2012, June). Industry overview: Industry skills and workforce development report for the health and community services industry. Brisbane: Health and Community Services Workforce Council Inc.

Hauck, S., Winsett, R. P., \& Kuric, J. (2013). Leadership facilitation strategies to establish evidence-based practice in an acute care hospital. Journal of advanced nursing, 69(3), 664-674

Hodkinson, P., Biesta, G., \& James, D. (2008). Understanding learning culturally: Overcoming the dualism between social and individual views of learning. Vocations and Learning, 1, 27-47.

Hugo, G. (2007). Contextualising the 'crisis in aged care' in Australia: A demographic perspective. Australian Journal of Social Issues, 42(2), 169-182.

Hugo, G. (2009). Care worker migration, Australia and development. Population, Space and Place, 15(2), 189-203.

Kay, K., \& Glass, N. (2011). Debunking the manual handling myth: An investigation of manual handling knowledge and practices in the Australian private health sector. International Journal of Nursing Practice, 17, 231-237. 
Liveng, A. (2010). Learning and recognition in health and care work: An inter-subjective perspective. Journal of Workplace Learning, 22(1-2), 41-52.

Loftin, C., Davis, L. A., \& Hartin, V. (2010). Classroom participation: A student perspective. Teaching and Learning in Nursing, 5, 119-124.

Mannix, E., \& Neale, M. A. (2005). What differences make a difference? The promise and reality of diverse teams in organisations. Psychological Science in the Public Interest, 6(2), 31-55.

Manthorpe, J., \& Martineau, S. (2008). Support workers: Their roles and tasks. A scoping review. University of London: Social Care Workforce Research Unit.

Markannen, P., Quinn, M., Galligan, C., Sama, S., Brouillette, N., \& O’Keyer, D. (2014).

Characterizing the nature of home care work and occupational hazards: A developmental study. American Journal of Industrial Medicine, 57, 445-457.

Martimo, K. P., Verbeek, J., Karppinen, J., Furlan, A. D., Takala, E. P., Kuijer, P. P. F., ... ViikariJuntura, E. (2008). Effect of training and lifting equipment for preventing back pain in lifting and handling: Systematic review. BMJ, 336(7641), 429-431.

Martin, B., \& Healy, J. (2010, August). Who works in community services? (Report of research funded by the Community and Disability Services Ministers Advisory Council, directed by its Structural Issues in the Workforce Subcommittee). Flinders University, Adelaide, Australia: National Institute of Labour Studies.

Meagher, G. (2006). What can we expect from paid carers? Politics and Society, 34(1), 33-53.

Melnyk, B. M., Gallagher-Ford, L., Long, L. E., \& Fineout-Overholt, E. (2014). The establishment of evidence-based practice competencies for practicing registered nurses and advanced practice 
nurses in real-world clinical settings: proficiencies to improve care quality, reliability, patient outcomes, and costs. Worldviews on Evidence-Based Nursing, 11(1), 5-15.

Merriam, S. B. (2014). Qualitative research: A guide to design and implementation. San Francisco, CA: John Wiley \& Sons.

Mott, S., Chau, A., \& Chan, J. (2007). Meeting the health needs of people with disability living in the community. Journal of Intellectual and Developmental Disability, 32(1), 51-53.

Nay, R., \& Garratt, S. (2002). Nursing older people. Issues and innovations. Sydney, MacLennan \& Petty.

Nursing home found in breach of act over accident with a hoist. (2008, July 9). Aged Care Crisis. Retrieved from http://www.agedcarecrisis.com/index.php/news/68-media/2965-nursing-homefound-in-breach-of-act-over-accident-with-a-hoist

Orr, J. (1990). Sharing knowledge, celebrating identity: War stories and community memory in a service culture. In D. S. Middleton \& D. Edwards., (Eds.), Collective remembering: Memory in society (pp. 169-189). Newbury Park: Sage.

Palesy, D. (2015). 'Learning occupational practice in the absence of expert guidance: A case study of in-home disability support workers' (Doctoral Dissertation, Griffith University, Queensland, Australia).

Pea, R. D. (1987). Socialising the knowledge transfer problem. International Journal of Educational Research, 11, 639-663.

Perkins, D., Jay, E., \& Tishman, S. (1993). Beyond abilities: A dispositional theory of thinking. Merrill-Palmer Quarterly, 39(1), 1-21. 
Pijl-Zieber, E. M., Barton, S., Konkin, J., Awosoga, O., \& Caine, V. (2014). Competence and competency-based nursing education: Finding our way through the issues. Nurse Education Today, 34(5), 676-678.

Prawat, R. S. (1989). Promoting access to knowledge, strategy, and disposition in students: A research synthesis. Review of Educational Research, 59(1), 1-41.

Radford, K., Shacklock, K., \& Bradley, G. (2015). Personal care workers in Australian aged care: retention and turnover intentions. Journal of nursing management, 23(5), 557-566.

Rimfire Resources \& NDS Australia. (2010). Disability services workforce data project. Melbourne: National Disability Services (NDS) Victoria for Disability Service, Department of Human Services.

Royer, J. M. (1979). Theories of the transfer of learning. Educational Psychologist, 14,_53-69.

Ryle, G. (1949). The concept of mind. London: Hutchinson University Library

Safe Work Australia. (2014). Key work health and safety statistics Australia 2014. Canberra: Commonwealth Government of Australia.

Sawyer, R. K. (Ed.). (2006). The Cambridge handbook of the learning sciences. New York: Cambridge University Press.

Scandura, J. M. (1973). Structural learning I: Theory and research. London: Gordon \& Breach.

Scandura, J. M. (1984). Structural (cognitive task) analysis: A method for analyzing content. Part II: Precision, objectivity and systematization. Journal of Structural Learning, 8, 1-27.

Somerville, M. (2006a). Becoming - worker: Vocational training for workers in aged care. Journal of Vocational Education and Training, 58(4), 471-481. 
Somerville, M. (2006b). Subjected bodies, or embodied subjects: Subjectivity and learning safety at work. In S. Billett, T. Fenwick, \& M. Somerville (Eds.), Work, subjectivity and learning (pp. 37-52). Netherlands: Springer.

Somerville, M., \& Bernoth, M. (2001). Safe bodies: Solving a dilemma in workplace education. Paper presented at the Ninth Annual International Conference on Post Compulsory Education and Training, Griffith University, Brisbane.

Stevenson, J. C. (1994). Vocational expertise. In J. C. Stevenson (Ed.), Cognition at work: The development of vocational expertise (pp. 7-35). Adelaide, South Australia: National Centre for Vocational Education Research.

Stone, R., Sutton, J., Bryant, N., Adams, A., \& Squillace, M. (2013). The home health workforce, a distinction between worker categories. Home Health Services Quarterly, 32(4), 218-233.

Thomas, D. (2006). A general inductive approach for analyzing qualitative evaluation data. American Journal of Evaluation, 27(3), 237-246.

Tuohy-Main, K. (1997, August). Prevention of manual handling injuries to residents in aged care. Paper presented at International Gerontology Congress, Adelaide, Australia.

Walkin, L. (2000). Teaching and learning in further adult education. Cheltenham: Stanley Thomes Publishers Ltd.

Wertsch, J. V. (Ed). (1985). Culture, communication and cognition: Vygotskian perspectives. Cambridge: Cambridge University Press.

Wiersma, W. (2009). Research methods in education. New Delhi: Pearson Education India.

Wood, D., Bruner, J., \& Ross, G. (1976). The role of tutoring in problem solving. Journal of Child Psychology and Psychiatry and Allied Disciplines, 17, 89-100. 
Zemlin, C. (2014). Transfer and implementation of knowledge and attitude - A particular challenge for caregivers in dementia care. Journal of Nursing Education and Practice, 4(1), 81-87. 